\title{
Treatment of periodic leg movements with a dopaminergic agonist in subjects with total spinal cord lesions
}

\author{
M Túlio de Mello*,1,2, DL Poyares ${ }^{1}$ and S Tufik ${ }^{1}$ \\ ${ }^{1}$ Department of Psychobiology, Universidade Federal de São Paulo, Brazil; ${ }^{2}$ Universidade Federal de Uberlândial \\ DEEFE/NIFEP
}

\begin{abstract}
Objective: To investigate the effect of L-dopa on the PLM/h index of spinal cord injured subjects.

Setting: São Paulo, Brazil.

Methods: Thirteen male volunteers with spinal cord section between T7-T12, and mean age of $31.6 \pm 8.3$ years participated in the study. L-dopa or placebo were administered for 30 days, $1 \mathrm{~h}$ before the volunteers went to sleep, in a double blind, crossover design. Polysomnographic recordings were performed on ten occasions: Phase 1: Basal night, following an adaptation night at the sleep laboratory; phase 2: after 1, 7, 21 and 30 days of L-dopa administration; phase 3: first night of L-dopa or placebo withdrawal; phase IV: 1, 7, 21 and 30 days after placebo ingestion.

Results: The index of PLM/h on the first night of L-dopa or placebo withdrawal (phase III) was lower than on both the basal night and the first night of L-dopa treatment. At the time of polysomnographic analysis, volunteers were divided into two groups: index of PLM/h below five and those whose index was above five. Comparison between L-dopa and placebo treatments revealed that only those volunteers with an index above five revealed a reduction in PLM in L-dopa.

Conclusion: These results indicate that despite the spinal cord lesions, L-dopa treatment is capable of minimizing PLM during sleep.
\end{abstract}

Keywords: sleep; spinal cord lesion(s); L-dopa; periodic leg movements (PLM); paraplegic; restless legs syndrome (RLS)

\section{Introduction}

The restless legs syndrome (RLS) was originally described in the general population by Ekbom. ${ }^{1}$ Later, an association between RLS and periodic leg movements (PLM) was reported. ${ }^{2,21}$ These disturbances may result in decreased sleep efficiency and sleep quality. A relation between dopaminergic deficit and $\mathrm{PLM} / \mathrm{RLS}^{3}$ as well as a reduction of dopaminergic $\mathrm{D}_{2}$ receptors in the basal ganglia of patients with PLM has been described. ${ }^{4}$

Several studies have reported favourable results of treatment of PLM with dopaminergic agonists. ${ }^{5-7}$ There is, however, a lack of consensus regarding dosage and length of administration of these drugs with therapeutic doses ranging between 100 and $250 \mathrm{mg}$ of L-dopa.

Recently, a high incidence of PLM and RLS in subjects with spinal cord lesions have been reported, ${ }^{8-12}$ allowing the possibility of identifying the origin of these abnormal movements. These subjects

*Correspondence: M Túlio de Mello, Department of Psychobiology, Universidade Federal de São Paulo, Rua Napoleão de Barros 925, Vila Clementino, São Paulo, SP 04020-002, Brazil spontaneously report sleep problems, and also even mention the need to be tied to the bed so as to avoid falling on the floor due to the frequency of lower limb movements during sleep. ${ }^{9}$ Moreover, reduction of the incidence of PLM and RLS following acute physical activity in these patients may be helpful for the identification of the mechanisms underlying PLM and RLS. ${ }^{10,13}$ Thus, it is possible that the reduction of limb movements may stem from endorphin secretion induced by physical activity, ${ }^{14}$ since treatment with opiates often results in a reduction of PLM and RLS. ${ }^{3}$ In addition, there is an important positive correlation between PLM and K complexes in spinal cord injured $^{10,11}$ and non-paraplegic subjects. ${ }^{3}$ To our knowledge, there is no study of PLM in spinal cord lesioned subjects treated with dopaminergic agonists.

It is known that dopamine plays an important role in motor activity in general. Demonstrably, dopaminergic agonists induce a decrease in motor activity. Tufik $^{15}$ highlighted the reduction in motor activity following administration of dopaminergic agonists in REM sleep deprived rats. Andrade ${ }^{16}$ reported the role played by dopamine on the pathophysiology of 
abnormal movements in Parkinsonian patients. Dopaminergic agonists have since been used in the treatment of movement disorders.

Maitra ${ }^{17}$ observed the involvement of the spinal cord in the pathophysiology of extrapyramidal motor disorders. There are motor nerve terminals containing muscarinic as well as inhibitory dopaminergic receptors that influence acetylcholine release at the spinal cord level. ${ }^{18}$ In order to study the inhibitory influence of the dopaminergic system on spinal cholinergic transmission, Maitra ${ }^{17}$ used a monosynaptic excitatory pathway from the collateral $\alpha$ motor axon of the Renshaw cells using apomorphine (a dopaminergic agonist) and sulpiride (a $\mathrm{D}_{2}$ dopaminergic antagonist). Based on their findings, the authors concluded that dopamine inhibited motor activity and influenced central acetylcholine transmission. We may conclude that dopaminergic receptors are clearly involved in the central modulation of cholinergic transmission originating in the collateral $\alpha$ motor axon of the Renshaw cells.

We therefore decided to test the hypothesis that abnormal movements in paraplegic subjects (PLM) have a similar origin to PLM found in non-paraplegic subjects. To this end, we treated such patients with Ldopa (200 mg) associated to $50 \mathrm{mg}$ to benzerazide (peripheral dopaminergic antagonist) as an attempt to observe only the central effects of this medication on $\mathrm{PLM} / \mathrm{h}$ indices in this specific population.

\section{Methods}

Thirteen male volunteers (mean age $=31.6 \pm 8.3$ years), with complete spinal cord lesion, between $\mathrm{T} 7$ and $\mathrm{T} 12$, were selected following contact through associations for the disabled in the state of São Paulo, Brazil. The subjects were submitted to clinical/neurological and neuroimaging evaluation to confirm the diagnosis.

L-Dopa $(200 \mathrm{mg})$, in assocation with benzerazide chloride $(50 \mathrm{mg})$, or placebo was administered for 30 days, $1 \mathrm{~h}$ prior to sleep time. This period of drug administration was followed by a 15-day period of washout, in a double-blind, crossover design. The subjects were divided into two groups, Group 1 receiving placebo whilst Group 2 were administered L-dopa (200 mg) associated to Benzerazide (50 mg). Polysomnographic (PSG) data (total of 130 recordings) were obtained in the following manner: Phase 1A: basal PSG; Phase 2A: PSG in 1, 7, 21 and 30 days; Phase 3A: PSG day 1 after drug or placebo withdrawal; Phase 1B: after 15 days of washout (second basal PSG for readaptation); Phase 2B: PSG 1, 7, 21 and 30 days; Phase 3B: PSG day 1 after drug or placebo withdrawal. In accordance with the crossover design, all volunteers received L-dopa (200 mg) associated to benzerazide (50 mg) and placebo.

Volunteers slept on two consecutive nights for basal evaluation in which the first night served as an adaptation night. Polysomnographic recordings were taken on the second night.
There was a similar second adaptation (readaptation) in the period preceding phase IIB as volunteers had spent 15 days away from the environment of our sleep laboratory.

Polysomnography was performed according to Rechtschaffen and Kales $^{19}$ and electrode placement was carried out according to the $10-20$ system. $^{20}$ Recordings were obtained using the Oxford/Medilog system (12 channels), with three channels for EEG, three channels for EMG (two on the legs and one on the chin), two channels for EOG, one channel for ECG, one channel for airflow, and two channels for abdominal and thoracic respiratory movements.

According to criteria established by ASDA, pathological indices for PLM are above five movements per hour, in non paraplegic patients. To this end, in order to analyze our results, we decided to split the subjects into two groups. (Group 1) those with less than five movements per hour; (Group 2) those displaying more than five movements per hour. ${ }^{21}$

The Kolmorogov-Smirnov test was used to evaluate the normal distribution of the samples. Data was subsequently analyzed using the Kruskal-Wallis test, followed by the Friedman ANOVA and the Kendall coefficient of concordance test to compare the sleep parameters of groups $1(\leqslant 5 \mathrm{PLM} / \mathrm{h})$ and $2(>5 \mathrm{PLM} /$ h) under drug and placebo treatments. The Wilcoxon matched pair test was used to compare withdrawal night (phases $3 \mathrm{~A}+\mathrm{B}$ ) with basal night (phases $1 \mathrm{~A}+\mathrm{B}$ ), with first night of drug administration (phase $2 \mathrm{~A}+\mathrm{B}$ ), and with the first night of placebo administration. Comparison of total arousal among recordings of basal 1st, 7th, 21st, 30th nights of L-dopa treatment was performed by the paired Student's $t$-test. Comparison among treatment nights and the corresponding placebo nights was performed by the Student's $t$-test for independent samples. Arousal was considered when the event was longer than $3 \mathrm{~s}$, according to the criteria established by the American Sleep Disorders Association. ${ }^{22}$ Volunteers followed a specified dietary regime on the lines recommended for the entire duration of the study. ${ }^{23}$

\section{Results}

Despite a progressive decline of PLM absolute values throughout the period of L-dopa treatment, the reduction of abnormal movements of the lower limbs during sleep was not statistically significant in the group as a whole (Table 1).

The Wilcoxon matched pairs test was used to compare data from phase 3 (withdrawal) and data from phases 1 (basal) and 2 (first night of L-dopa administration). The analysis highlighted a significant reduction of the $\mathrm{PLM} / \mathrm{h}$ index (phase $3 \times$ phase 1; $P<0.01$ and phase $3 \times$ phase $2 ; P<0.03)$.

When both groups 1 (index of PLM/h below five) and 2 (index of PLM/h above five) were analyzed separately, no statistical difference between phases 2 (L-dopa) and 3 (withdrawal) was observed for group 
Table 1 Mean (SD) index of PLM/h observed on basal night (phase 1), L-dopa treatment (phase 2), withdrawal night (phase 3), and placebo treatment (phase 4) in spinal cord injured subjects

\begin{tabular}{|c|c|c|c|c|c|c|c|c|c|}
\hline Phase 1 & & $\begin{array}{r}P h \\
L-d o p a\end{array}$ & $\begin{array}{l}\text { e } 2 \\
\text { eatment }\end{array}$ & & Phase 3 & & & & \\
\hline Basal & Night 1 & Night 7 & Night 21 & Night 30 & Withdrawal & Night 1 & Night 7 & Night 21 & Night 30 \\
\hline $\begin{array}{c}35.11 \\
(41.98)\end{array}$ & $\begin{array}{c}31.48 \\
(38.40)\end{array}$ & $\begin{array}{c}29.04 \\
(50.12)\end{array}$ & $\begin{array}{c}28.24 \\
(40.36)\end{array}$ & $\begin{array}{c}22.26 \\
(33.15)\end{array}$ & $\begin{array}{l}19.87 * \# \\
(25.46)\end{array}$ & $\begin{array}{c}28.94 \\
(37.24)\end{array}$ & $\begin{array}{c}41.10 \\
(53.52)\end{array}$ & $\begin{array}{c}36.66 \\
(44.14)\end{array}$ & $\begin{array}{c}32.52 \\
(45.70)\end{array}$ \\
\hline
\end{tabular}

*Differs from phase 1; $P<0.01$. \#Differs from phase 2, Night $1 ; P<0.03$

Table 2 Mean (SD) index of PLM/h of groups 1 (index of $\mathrm{PLM} / \mathrm{h}$ below five) and 2 (index of PLM/h above five) during treatment with L-dopa and placebo

\begin{tabular}{lcc}
\hline & $\begin{array}{c}\text { Group 1 } \\
(\mathrm{PLM} / \mathrm{h}<5)\end{array}$ & $\begin{array}{c}\text { Group 2 } \\
(\mathrm{PLM} / \mathrm{h}>5)\end{array}$ \\
\hline L-dopa & $2.28(2.34)$ & $49.59(36.39)^{*}$ \\
Placebo & $2.63(1.96)$ & $62.38(33.94)$ \\
\hline
\end{tabular}

*Differs from placebo treatment, only in group $2 ; P<0.006$. Group 1: $n=12$ Group 2: $n=14$

1. However, Group 2 revealed a significant reduction of abnormal lower limb movements during L-dopa administration $(P<0.006)$.

There were no statistical differences on total number of arousals, despite a PLM reduction induced by treatment with L-dopa. In regard to the apnea/ hypopnea index, our sample presented indices within the normal range.

\section{Discussion}

Lesions or injury of the spinal cord at the cervical, thoracic or lumbar levels determine paraplegic or tetraplegic conditions. Subjects bearing this kind of lesion exhibit several sequelae such as decreased motor activity, muscle atrophy, reduction and impairment of metabolic and cardiac activity, as well as the decline of physical capacity. ${ }^{23}$

In spinal cord injured (at the level of T7-T12) subjects, abnormal lower limb movements (PLM) could be influenced by dopamine at the spinal level. ${ }^{24,25}$ Consequently, the dopaminergic inhibitory role on abnormal motor activity is impaired by the spinal cord lesion, and might be restored by treatment with L-dopa associated with benzerazide as suggested by the above results. Another possible explanation for the lack of reduction on the number of arousals might be the occurrence of respiratory events during sleep. Nonetheless, our volunteers presented an apnea/ hypopnea index within normal values, detected by the airflow technique. Still, it is not possible to reject the occurrence of altered upper airway resistance, which might have maintained the high levels of arousal. These data may also suggest that the arousal mechanism associated with abnormal movements is impaired in subjects bearing spinal cord lesion; with the lack of sensitivity below the level of the lesion the stimulus generated by the abnormal movements would not be perceived and would not result in arousal. It is not easy to explain how the transmission of an excitatory stimulus (highly likely to be generated in the basal ganglia) might produce movements below the level of a complete spinal cord injury. Even more surprising are the volunteers' responses to the treatment L-dopa + benzerazide. One hypothesis to account for this imbalance may involve the maintenance of a monosynaptic pathway, ${ }^{17}$ capable of regulating the transmission of dopaminergic stimuli. Dopamine, by stimulating dopaminergic $\mathrm{D}_{2}$ receptors, might inhibit central cholinergic transmission yielding a neurochemical balance (excitatory/inhibitory) which would prevent the occurrence of such abnormal movements. In our group of paraplegic subjects with complete spinal cord lesions, this monosynaptic pathway may be compromised permitting the appearance of such abnormal movements (PLM). Exogenous L-dopa, seemingly, would reinstate this balance, reducing abnormal movements of the lower limbs.

In the present study, L-dopa was administered $1 \mathrm{~h}$ before bed time, which might have resulted in a possible drop in the compound's concentration during the final third of the night, thus reducing the drug's efficacy on the PLM index. The use of a controlledrelease L-dopa could be a useful strategy in future studies, in order to reduce this problem.

\section{Acknowledgements}

This work was supported by the 'Associação Fundo de Incentivo à Psicofarmacologia' (AFIP) and the 'National Institute for the Development of Sports' (INDESP). The authors are also indebted to the Brazilian Ministry of Sports for invaluable assistance at all stages of the study.

\section{References}

1 Ekbom KA. Restless legs. Acta Med Scand (Suppl) 1945; 158: 123.

2 Coleman RM, Pollak CP, Weitzman ED. Periodic movements in sleep (nocturnal myoclonus): Relation to sleep disorders. Ann Neurol 1980; 8: 416-421. 
3 Montplaisir J, Lorrain D, Godbout R. Restless legs syndrome and periodic leg movements in sleep. The primary role of dopaminergic mechanism. Eur Neurol 1991; 31: 41 - 43.

4 Brodeur C, Montplaisir J, Godbout R, Mariner R. Treatment of restless legs syndrome and periodic movements during sleep with L-dopa. A double-blind, controlled study. Neurology 1988; 38: $1845-1848$.

5 Staedt J, Stoppe G, Kogler A, Munz D, Riemann H, Emirich D, Ruther E. Dopamine $\mathrm{D}_{2}$ receptor alteration in patients with periodic movements in sleep (noctural myoclonus). J Neural Trans 1993; 93: $71-74$.

6 Montplaisir J, Godbout R, Poirier G, Bédard MA. Restless legs syndrome and periodic movements in sleep. Physiopathology and treatment with L-dopa. Clin Neuropharmacol 1986; 9: 456-463.

7 Montplaisir J, Godbout R, Pelletier G, Warnes H. (1994) Restless legs syndrome and periodic limb movements during sleep. In: Kryger, MH, Roth T, Dement WC (eds). Principles and practice of sleep medicine 2 nd edn., W.B. Saunders Company: Philadelphia, pp. 589.

8 Takanori I, Kazuhiko H, Hitoshi T. Sleep related periodic leg movements (nocturnal myoclonus) due to spinal cord lesion. $J$ Neurol Sci 1991; 104: 13-18.

9 Mello MT, Natal CL, Cunha JM, Tufik S. Epidemiololgia do padrão de sono em adultos desportistas portadores de lesão medular. Rev Port Med Desp 1995; 13: 89-100.

10 De Mello MT, Da Silva AC, Tufik S. Sleep study after acute physical activity in spinal cord injury. Sleep Res 1995; 24A: 391

11 De Mello MT, Silva AC, Rueda AD, Tufik S. Correlation between $\mathrm{K}$ complex, periodic leg movements (PLM), and myoclonus during sleep in parapletic adults before and after acute physical activity. Spinal Cord 1997; 35: $248-252$.

12 Dickel MJ, Renfrow SD, Moore PT, Berry RB. Rapid eye movement sleep periodic leg movements in patients with spinal cord injury. Sleep 1994; 17: 733-738.

13 De Mello MT, Lauro FAA, Silva AC, Tufik S. Incidence of periodic leg movements and of the restless legs syndrome during sleep following acute physical activity in spinal cord injury subjects. Spinal Cord 1996; 34: 294-296.

14 Schwarz L, Kinderman W. Changes in $\beta$-endorphin levels in response to aerobic and anaerobic exercise. Sports Med 1992; 13: $25-36$.
15 Tufik S. Changes of response to dopaminergic drugs in rats submitted to REM-sleep deprivation. Psychopharmacology 1981; 72: $257-260$

16 Andrade LAF, Lima JGC, Tufik S, Bertolucci PHF, Carlini EA. REM sleep deprivation in an experimental model of Parkinson's disease. Arq Neuropsiquiatr 1987; 45: 217-223.

17 Maitra KK, Seth P, Thewissen M, Ross HG, Ganguly DK. Dopaminergic influence on the excitability of antidromically activated Renshaw cells in the lumbar spinal cord of the rat. Acto Physiol Scand 1993; 148: 101-107.

18 Ganguly DK, Das M. Effects of oxotremorine demonstrate presynaptic muscarinic and dopaminergic receptors on motor nerve terminals. Nature 1979; 278: $645-646$.

19 Rechtschaffen A, Kales A. (1968). Manual of standardized terminology technique and scoring for sleep stages of human subjects. 4th edn. UCLA: Los Angeles.

$20 \mathrm{Jasper}$ HH. The ten-twenty electrode system of the international federation. Eletroencephalogr Clin Neurophysiol 1958; 10: 371 375.

21 Walters AS et al. Towards a better definition of the restless legs syndrome. The International Restless Legs Syndrome Study Group. Mov Disord 1995; 37: 82 - 84

22 American Sleep Disorders Association. EEG arousals: scoring rules and examples. Sleep 1992; 15: $173-184$.

23 Scalzo FM. (1992). Prolonged dietary restriction and its effect on Dopamine systems of the brain. In: Robert L. Isaacson and Kar F. Jensen (eds). The Vulnerable Brain and Environmental Risks, vol 1: Malnutrition and Hazard Assessment. Plenum Press: New York.

24 Wick JR, Lymburned K, Dinsdale SM, Jones NL. The use of multistage exercise testing with wheelchair ergometry and arm cranking in subjects with spinal cord lesions. Paraplegia 1977; 15: $252-261$

25 Smith DO, Lowe D, Temki R, Jensen P, Hatt H. Dopamine enhances glutamate-activated currents in spinal motoneurons. $J$ Neurosci 1995; 15: $3905-3912$. 